\title{
Technology transfer of the military-industrial complex as a factor in increasing the science intensity of the civilian industry
}

\author{
Daria Akimkina ${ }^{1}$, Evgenii Khrustalev ${ }^{1}$, Nina Baranova, ${ }^{2, *}$, and Daria Loginova ${ }^{1,2}$ \\ ${ }^{1}$ Laboratory of simulation modeling of the interaction of economic objects, Central Economics and \\ Mathematics Institute RAS (CEMI RAS), 47, Nakhimovsky prospect, 117418 Moscow, Russia \\ ${ }^{2}$ Faculty of Economics, Department of Economic and Mathematical modeling, \\ Peoples' Friendship University of Russia (RUDN University), 6, Miklukho-Maklaya Str, 117198 \\ Moscow, Russia
}

\begin{abstract}
The high innovation potential of the Russian military-industrial complex can become a source of technology for the civilian industry. In the context of the diversification of the military-industrial complex, the development of an effective technology transfer can become one of the key elements in building a competitive Russian economy. The article contains a diagram of the mechanism for the innovative technology development and transfer between the military and civilian sectors. On the basis of this method, it is possible to build effective schemes for technology transfer and exchange and joint work of the military and civilian industries. The emergence of a technology broker, as an intermediary between the military-industrial and civilian complexes, will accelerate the development of active information and scientific exchange between these sectors, will make it possible to bring technologies to its implementation faster, and industries become more knowledge-intensive. Integration of the military and civilian sectors will help to reduce the technological gap within the country, lagging behind the world level.
\end{abstract}

\section{Introduction}

The rapidly growing globalization directly affects all areas of activity of any country: economic, political, social, cultural. On the one hand, close international cooperation leads to an increase in the communication speed and method, a rise in the number of partnership approaches, the international capital flow, migration, etc. On the other hand, this aggravates a number of problems: economic instability, the gap between wealth and poverty, technological gap, national safety, etc.

In the pre-crisis conditions, Russia pinned great hopes on such a form of cooperation as technology borrowing in order to reduce the technological gap. In the context of antiRussian sanctions and access restriction to foreign technologies, an alternative source of advanced technologies must be found [1].

\footnotetext{
*Corresponding author: baranova_nm@pfur.ru
} 
The R\&D development and introduction requires high expenditures, long lapse of time and availability of highly qualified staff. This process is always associated with risks of various sorts: economic, scientific and technical, engineering and production, that not all of enterprises are ready and able to bear.

The military-industrial complex (MIC) can become a launch pad for the breakthrough technologies development in both the military-industrial and civilian industries. It is this complex that has recently been well funded by the state, is engaged in research and development and has highly qualified staff. Therefore, a study of the process of the advanced technologies transfer from the military-industrial complex to the civilian must be conducted and vice versa, to study its shortcomings.

\section{Materials and Methods}

The paper studied the scientific works of Russian and foreign scientists, devoted to various aspects of the process of technologies transfer and renewal. In Russia, such studies were carried out by the scientists Khrustalev E. Yu., Batkovsky A.M., Semenova E.G., Fomina A.V., Khrustalev O.E. [2-3] and others. The researches of the scientists Batkovsky A.M. [3], Slavyanov A.S., Khrustalev E. Yu. [4] Anischenko T.V. [5] and others are devoted to the military-industrial complex diversification and the possibility of using military technologies. The proceedings of Ignatova A.I. and others [6] are devoted to the study of the technology transfer system in Russia. The proceedings of such scientists as Zharova E.N., Gribovsky A.V. [7] and others focused on the assessment of the technology transfer efficiency, demand assessment and search for market outlets.

The foreign scientists have also investigated various components of the technology transfer process from the military to the civilian area - Bukkvoll T., Malmlöfb T., Makienko K. [8], etc. considered the conditions that would facilitate this process. Van Norman, Eisenkot R. [9], etc. analyzed the technology transfer process from a legal standpoint. Schmid J. [10] et al. examined the impact of government funding on R\&D. The researches of Anischenko T.V., Mendi A.F., Nacar M.A., Solmaz M. [11], Bozeman B. [12] and others are devoted to the issues of functioning and building a business model within the framework of technology transfer.

The technology transfer is discussed in the articles by Li Yang, Hu Wang [13], Yuan Z. [14], Bakulina A.A., Sokolova E.S. [15], etc. The integration of the military and civil sectors of China is studied by Ng J. C. Y., Song K. K. W., Tan Q [16].

The issue of the impact of technology transfer on the science intensity growth and the technological level of civilian industry is not sufficiently covered in the economics literature, despite a large number of studies on the technology transfer from the militaryindustrial complex to the civilian. The synthesis method and comparative analysis are used to study this issue. The comparative analysis method is needed to analyze the experience of technology transfer from the MIC for the development of civilian products in Russia and abroad. The synthesis method delivers to construct a diagram of the development and technology transfer stages and highlight the main directions for further improving this process.

\section{Results}

The MIC is a tech-intensive sector that can be a scientific and technological base for innovation-driven growth. Many technologies came to the civilian sector from the military sphere during the period of hostilities [17]. The military technologies transfer contributed to 
the emergence of the Internet, GLONASS, GPS, satellite communication and television, jet passenger aviation, etc. [4]

The diversification of high-tech industries, including the MIC, determined the fundamental directions of Russian industrial policy [15]. The State Program "Scientific and Technological Development of the Russian Federation" (2019-2030) identified a problem hampering scientific and technological development. It is a lack of technology and knowledge transfer between the military and civil sectors.

The technology transfer [12] is defined as the process of transition of technologies and the corresponding rights to them, knowledge, skills, production methods from the transferring party to the receiving party for the purpose of their subsequent implementation and use [18]. The diagram of technology development and transfer between the military and civilian sectors and their relationship was developed for illustration purposes (Fig. 1).

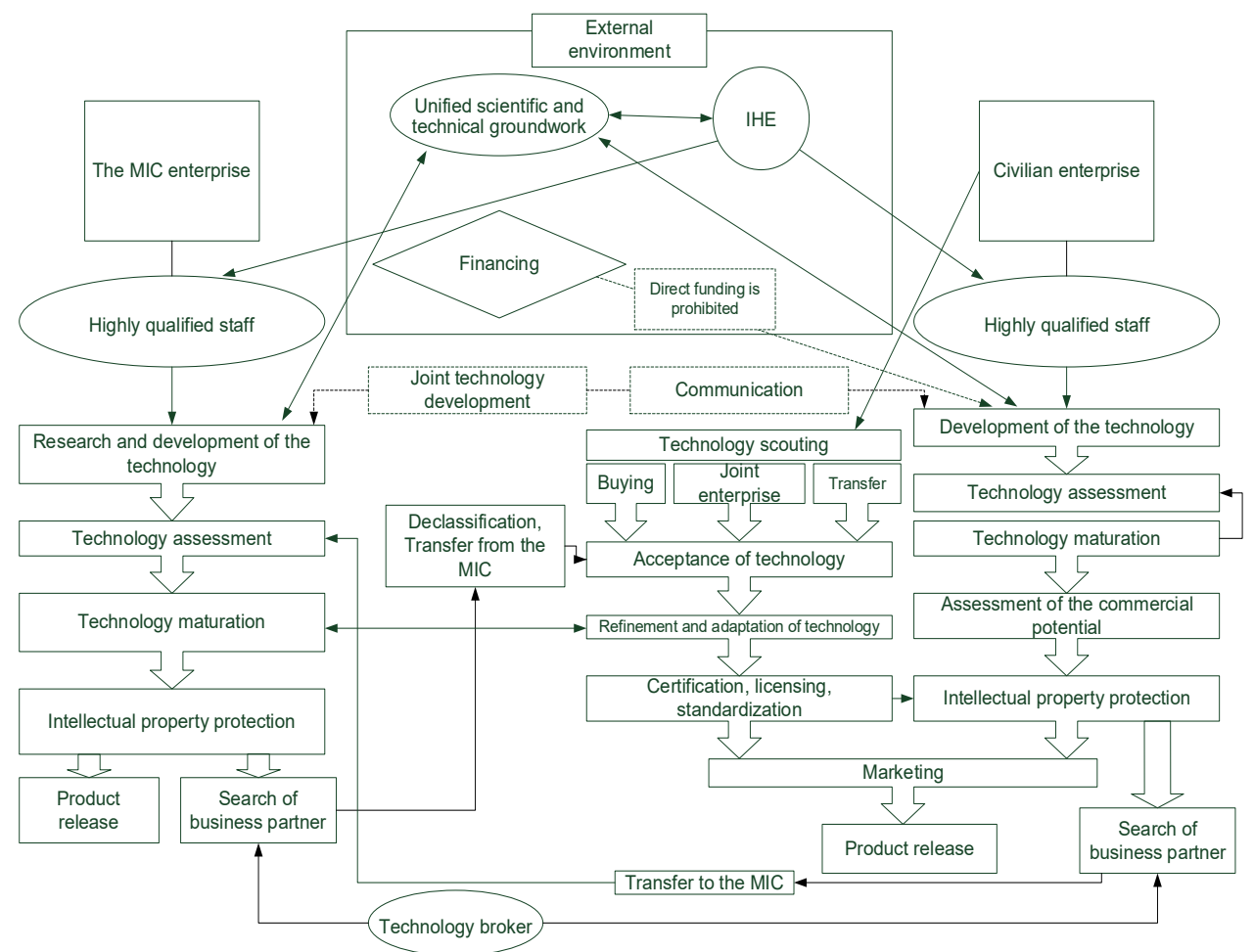

Fig. 1. The technology development and transfer stages. Source: prepared by the authors [19].

The creation and development of R\&D for military and civilian enterprises requires highly qualified staff, a scientific and technological base, and funding [7].

The stages of technology development at military and civilian enterprises are basically the same (Fig. 1). At a military enterprise, this process has the stages as follows:

1) research and development of technologies;

2) technology assessment;

3) technology maturation (development of technologies, prototype production of products);

4) intellectual property protection;

5) product release.

A civil enterprise innovation process needs to include two stages: assessment of the commercial potential of innovation and marketing. The competitive capacity of an 
enterprise directly depends not only on the innovation development, but also on its successful implementation. This should offset the costs of developing these technologies.

If a civil enterprise is short of resources to develop technologies on its own, it decides to borrow them. In this case, technologies can be obtained in several ways: acquisition of use right, foundation of a joint venture, or transfer. Moreover, the transfer has not always commercial nature. Since there is a ban on direct financing of commercial products, the military technology transfer can be a good alternative, since this does not apply to military developments [20]. This method of civil development support is widely used abroad. But there is a limitation - the transfer of military technologies to the civilian area is possible only after they go through the declassification procedure.

When the enabling technologies and the budget contributor are found, agreements are concluded, the technologies are accepted in compliance with all legal norms. Then the technologies should be further refined and adapted for civilian use through R\&D, manufacture a prototype of products, eliminate shortcomings, and improve technologies. Then the procedures of certification, licensing, standardization of products, marketing research, commercialization of products (service release), and product launch are carried out.

In the process of technological transfer, two-way relationships are established between the transmitting and receiving parties. And these relations do not end after the settlement of transaction, but are strengthened through the information and knowledge exchange, joint technology development, and military-civil integration. Such integration will reduce production costs, enter the civilian market and gain competitive experience for defense enterprises, and for civilian enterprises, it will accelerate the creation of innovative scienceintensive products with new consumer performance of civilian or dual-use. The long-term cooperation can help resolve any issues with production capacity.

When the integration scheme is implemented, the problem, as follows, on more than one occasion arises: military and civilian manufacturers may not know about each other or may not know how to establish a mutually beneficial relationship. That issue should be tackled through an intermediary required in the technology transfer, or a technology broker (Fig. 1). Its tasks include the search and selection of business partners, the establishment of relationships with them, assistance in the refinement and adaptation of technologies, legal protection, marketing research, the innovative environment formation $[5,8]$. The National Association for Technology Transfer (NATT) is an example of such a broker. The NATT carries out expert, consulting and educational activities in the technology transfer field, helps to take technologies to implementation faster, and to increase the science intensity of the industry.

\section{Discussion}

The technology transfer could become an effective mechanism for enhancing innovation processes in the civilian science-intensive industry. Defense technology can be used as a basis for civilian developments, reducing development and innovation costs and time. Civilian companies scarcely ever have the resources to innovations, and defense enterprises are better funded by the government. Therefore, the technology transfer can be regarded as a reallocation of funds, which will optimize the cost of budgetary funds to maintain scientific and technical potential.

The technology transfer from the civilian sector to the military is less frequent, since military technologies are usually more advanced, and civilian technologies, as a rule, are for commercial purposes [13]. However, there is a practice abroad of attracting private companies in the interests of production high-tech military products, for example, in the IT 
industry. For example, the US Department of Defense is involved in attracting small businesses to solve technological problems [15].

Integration and mutual enrichment of military and civilian technologies has a multiplier effect, which leads to increased flexibility in creating an innovative science-intensive product. The cooperation of military enterprises, joint project organization with private high-tech enterprises will permit defense enterprises to enter the market environment, learn how to manage risks, improve management efficiency, master cost-saving method, improve marketing and project management [21-22].

\section{Conclusions}

To sum up, the accumulated scientific and technical experience of the military sector can be effectively used in the process of scientific and technological modernization of mechanical engineering, increasing the level of its science intensity through the technology transfer. This will contribute to a reduction of the dependence on imports, foreign technologies and suppliers. Working with enterprises manufacturing components will contribute to the formation of a base of high-quality, reliable components in Russia, which is essential for the stable enterprise operation.

Medium-tech companies and industries can also accept technology assistance from the defense industry. This will contribute not only to the technological advancement of the industry, an increase in the high-tech products share, but also the transformation of the industry from the medium-tech to high-tech and science-intensive.

Integration of the military and civil areas would bring together efforts for technological advancement, reduce the technological gap within the country, and lag behind the world level. This will contribute to the development of the national competitiveness, sustainable economic growth, and national security.

\section{Acknowledgements}

The article was prepared with financial support by the Russian Science Foundation, grant № 21-78-20001 «Development of the theory and model tools for optimizing the management of the diversification of defense production in the context of the economic crisis and growing threats to Russia's national security».

\section{References}

1. N. M. Baranova, N. A. Shevtsova, E. G. Dmitrieva, Global Challenges and Prospects of the Modern Economic Development, 1, 1877 (2019)

2. E. Yu. Khrustalev, National Interests: Priorities and Security, 35, 61 (2011)

3. A. M. Batkovsky, E. G. Semenova, A. V. Fomina, E. Yu. Khrustalev, O. E. Khrustalev, Indian J. Sci. \& Technol., 9, 1 (2016)

4. A. S. Slavyanov, E. Yu. Khrustalev, Scientific J. of KubSAU, 6, 115 (2020)

5. T. V. Anischenko, Management of the economy, systems, processes, 1, 26 (2019)

6. A. I. Ignatova, http://nauchkor.ru/pubs (2016)

7. E. N. Zharova, A. V. Gribovsky, VUiT J. of Economics, 4, 1 (2017)

8. T. Bukkvoll, T. Malmlöf, \& K. Makienko, Post-Communist Economies, 29, 232 (2017)

9. G. A. Van Norman, R. Eisenkot, JACC: Basic to Translational Science, 2, 85 (2017) 
10. J. Schmid, Defence and Peace Economics, 29, 595 (2018)

11. A. F. Mendi, M. A. Nacar, M. Solmaz, ICTE, 1. (2020)

12. B. Bozeman, Research Policy, 29, 627 (2000)

13. Y. Li, P. Yang, J. Hu, Development of Marine Electronics and Communication Navigation Technology (2011)

14. Z. Yuan, Sci. and Technol. Management Research, 28, 487 (2008)

15. A. A. Bakulina, E. S. Sokolova, National security / nota bene, 5, 1 (2019)

16. J. C. Y. Ng, K. K. W. Song, Q. Tan, Int. J. of Innovation Studies, 2, 33 (2018)

17. WIPO2012, https://www.wipo.int (2012)

18. GOST R 57194.1-2016 (2016)

19. A. Yu. Pronin, VectorEconomy 12, 58 (2020)

20. A. B. Slivitsky, Russia: Trends and Development Prospects, 12, 421 (2017)

21. O. V. Samovarova, S. V. Zhurkina, E. A. Gorin, Innovation, 9, 9 (2019)

22. A. V. Kirsanova, Innovation and investment, 2, 232 (2018) 